\title{
Processos cognitivos na diferenciação e aplicabilidade dos conceitos de equação e função na química
}

André Luis Andrejew Ferreira

Orientador: Milton Antônio Zaro

Coorientador: Marcus Vinicius de Azevedo Basso

Data da defesa: 8 de janeiro de 2010

O presente trabalho tem como objetivo investigar a compreensão dos conceitos de equação e função que serão aplicados na disciplina de Física-Química do curso de Química da Universidade Federal de Pelotas. Para isso será usado como fundamentação teórica a aprendizagem significativa de Ausubel, os conceitos matemáticos de equação e função aplicados à Química, assim como a análise e levantamento de ferramentas computacionais disponíveis na internet e as suas características em termos de aplicabilidade na área do ensino. Para a realização dessa pesquisa será realizado pré-teste com os alunos matriculados na referida disciplina, visando identificar os subsunçores matemáticos adquiridos até o momento. O pré-teste, também, possibilitará a elaboração de um mapa conceitual sobre esse o conhecimento matemático adquirido, permitindo assim apontar requisitos para desenvolver um objeto de aprendizagem que permita ao aluno interagir com esse através da internet. O objeto de aprendizagem possibilitará ao aluno o processo de interação visando desenvolver a sua aprendizagem, assim como disponibilizará elementos que promovam a interdisciplinaridade entre a matemática e a química. A interdisciplinaridade privilegiará a aplicabilidade de conceitos matemáticos aplicados na Química, especificamente na disciplina de Fisico-Química do curso de graduação.

Palavras-chave: Subsunçores. Interdisciplinaridade. Mapas Conceituais. Aplicabilidade de Conceitos. Físico-Química I.

FERREIRA, André Luis Andrejew. Processos Cognitivos na Diferenciação e Aplicabilidade dos Conceitos de Equação e Função na Química. Orientador: Milton Antônio Zaro. Coorientador: Marcus Vinicius de Azevedo Basso. Tese (Doutorado) - Programa de Pós-Graduação em Informática na Educação, CINTED/UFRGS, 2010, Porto Alegre, BR-RS. 